\title{
Trends in scientific communication and continuing education in Forensic Sciences during the pandemic of COVID-19: The role of virtual conferences and experiences of the 2020 Online Congress of the Brazilian Society of Forensic Sciences
}

\author{
Eduardo Geraldo de Campos ${ }^{1}$, Daniel Junqueira Dorta² ${ }^{\text {D }}$, Bruno Spinosa De MartinisiD \\ ${ }^{1}$ Departamento de Análises Clínicas, Toxicológicas e Bromatológicas da Faculdade de Ciências Farmacêuticas \\ de Ribeirão Preto, Universidade de São Paulo, Av. do Café s/n, Ribeirão Preto, 14040-903, São Paulo, Brazil \\ ${ }^{2}$ Departamento de Química, Faculdade de Filosofia, Ciências e Letras de Ribeirão Preto, Universidade de São \\ Paulo, Av. Bandeirantes, 3900, Ribeirão Preto, 14040-901, São Paulo, Brazil
}

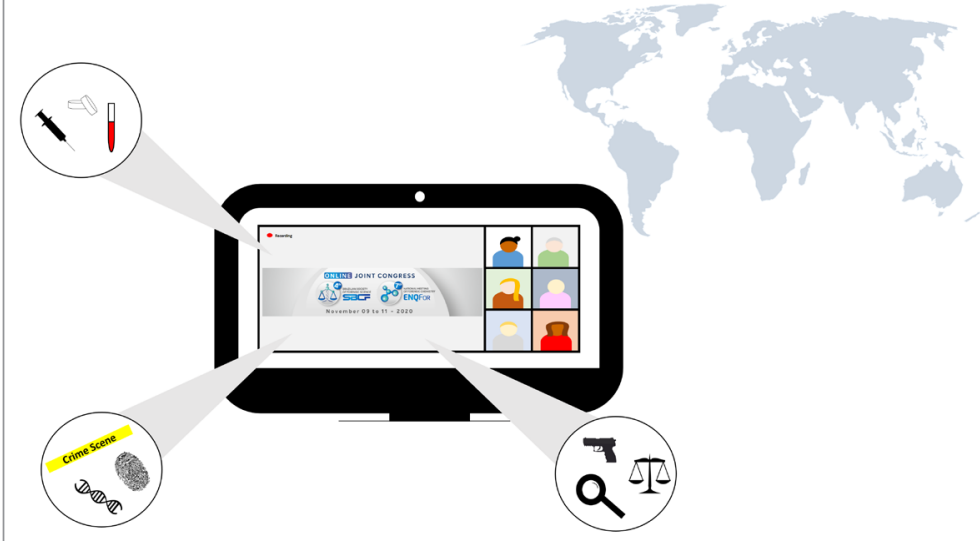

Some of these images were royalty free retrieved from Pixabay (https:// pixabay.com/pt/)
The pandemic of COVID-19 has changed the landscape of scientific meetings in 2020 , leading to the cancellation, postponement or change of format in many conferences. The latter type of change involved the conversion of in-person to virtual meetings. The decision as well as the logistics involved in these changes are not easy. However, the benefits and gains provided by virtual scientific conferences through 2020 in many disciplines have shown that this format can overcome many challenges and promote the diversity in Forensic Sciences conferences as well. In this paper, the benefits and potentials of virtual conferences

in Forensic Sciences, including Forensic Chemistry and Toxicology, in promoting scientific communication, accessibility, diversity and continuing education is discussed, in the light of the experiences of the Brazilian Society of Forensic Sciences with the 2020 SBCF Online Congress. The experiences obtained with virtual scientific meetings in 2020 have shown that these formats are very promising and important, and should be increasingly incorporated in future scientific meetings, as an alternative strategy to promote scientific communication, reaching large audiences, without travel limitations and at reduced costs for the attendees.

Cite: Campos, E. G.; Dorta, D. J.; De Martinis, B. S. Trends in scientific communication and continuing education in Forensic Sciences during the pandemic of COVID-19: The role of virtual conferences and experiences of the 2020 Online Congress of the Brazilian Society of Forensic Sciences. Braz. J. Anal. Chem., 2022, 9 (34), pp 177-187. doi: http://dx.doi.org/10.30744/ brjac.2179-3425.AR-57-2021

Submitted 07 April 2021, Resubmitted 21 June 2021, Accepted 16 August 2021, Available online 03 September 2021. 
However, this approach should not replace in-person meetings, which have many benefits that cannot be replaced by virtual meetings. Therefore, the combination of online and in-person meetings can be very useful strategies.

Keywords: Virtual conferences, scientific communication, continuing education, Forensic Chemistry, Forensic Sciences

\section{INTRODUCTION}

The pandemic of COVID-19 has been affecting many people and sectors of our societies in 2020, with high death tolls, elevated rates of unemployment and many other problems. The research and development of vaccines for immunization against the SARS-CoV-2 has been growing in many countries but there is some uncertainty about when the vaccines will become highly available for the majority of the population, mainly in low-income countries. Therefore, for now, the World Health Organization (WHO) still recommends that mask use and social distancing are the best tools for protection against the COVID-19 and for reducing the virus spread [1]. In order to help the spread of the virus following these recommendations, many activities involving a high number of people have been postponed or cancelled in 2020 , which include scientific conferences.

Scientific conferences have been directly affected by the pandemic of COVID-19, leading to an impact on other related sectors as well. These conferences are of great importance in academia, industry, public service and more as they serve as an important way for scientific communication and exchange [2], building and fostering partnerships and collaborations, meeting colleagues and promotion of career/job opportunities [3]. In addition, the effects of the pandemic on the mental health of young people and adults due to social distance are quite worrying. The increase in the number of individuals with symptoms of depression, anxiety, distress, use and abuse of licit and illicit drugs during the pandemic is significant, and often leading to suicide attempts and consummation. Maintaining and increasing the promotion of scientific / social activities with the ultimate goal of promoting continuing education, even if it is in a virtual format, can be a way of easing the effects of the serious and sad situation that the world is facing. More specifically, in Forensic Sciences, including Forensic Chemistry and Toxicology, these conferences are a great opportunity for students and professionals from academia, crime laboratories, law enforcement and public health agencies, private laboratories to reunite and discuss the latest advancements within their fields, to present their research, to foster collaborations and to interact with peers. However, in these unprecedented times, when these conferences cannot be held in-person, these opportunities are missed.

In 2020, many important conferences have been cancelled or postponed [3]. The decision of cancelling such important and big events is not easy and involves many factors, especially considering the time lapse of just a few months to analyze the landscape and decide about the congress, as recently highlighted by some scientific societies organizing these meetings (e.g. [4,5]). On the other hand, with the pandemic of COVID-19 in 2020, many opportunities to organize and promote online conferences have arisen. Consequently, a high number of conferences and scientific meetings has been hosted online $[2,6]$, respecting the social distancing recommendations demanded to control the pandemic. In the field of Forensic Sciences many events were hosted during the pandemic in 2020 and early 2021: the inaugural meeting of the International Alliance of Clinical and Forensic Toxicologist (IACFT) [7], the 2020 and 2021 Online Forensic Symposium Series [8-10], The International Association of Forensic Toxicologists (TIAFT) Online Educational Symposium [11], 73 ${ }^{\text {rd }}$ American Academy of Forensic Sciences Annual Scientific Meeting (United States) [12], which also include the meeting of the Brazilian Society of Forensic Sciences (SBCF) [13]. 


\section{HOSTING A VIRTUAL CONFERENCE IN 2020: EXPERIENCES OF THE BRAZILIAN SOCIETY OF FORENSIC SCIENCES (SBCF)}

The Brazilian Society of Forensic Sciences (SBCF) is "a non-profit association whose objective is to promote research and teaching in Forensic Sciences, to stimulate contact between professionals in the area and to promote the progress of Forensic Sciences in Brazil" [14]. SBCF was founded in 2013 by professors of the BSc in Chemistry with a Major in Forensic Chemistry Program of the Department of Chemistry at University of São Paulo, in Ribeirão Preto, Sao Paulo State, Brazil, and since then has been hosting biannual in-person meetings in Brazil, jointly with the National Meeting of Forensic Chemistry (ENQFor). In 2020, the SBCF Online Joint Congress $-4^{\text {th }}$ Meeting of the SBCF and the $7^{\text {th }}$ National Meeting of Forensic Chemistry (ENQFor) was scheduled to be held in August 2020. However, due to the pandemic, the Congress was postponed to November 2020 and changed to an online format [13].

The SBCF Online Joint Congress (Meeting of the SBCF and the National Meeting of Forensic Chemistry) is already a traditional and expected Conference in Forensic Sciences communities in Brazil. The National Meeting of Forensic Chemistry has been hosted in Brazil since 2008 whereas the first meeting of the SBCF was hosted in 2014. The Conference is an invaluable opportunity to reunite students and professionals from different sectors to discuss the advances and challenges of Forensic Sciences in Brazil and abroad. Many of the students enrolled in the B.S. in Chemistry with a Major in Forensic Chemistry program, offered by the University of São Paulo in Brazil, attend the conference. It is a traditional conference on Forensic Chemistry in Brazil and a good opportunity to meet important professors and researchers in the field as well as to present research results, which may be developed during their internships.

Based on all these aspects, the decision regarding hosting or not the Congress in 2020 was very difficult for the Board of Directors of the SBCF and the 2020 Organizing Committee. In the early stages of the pandemic in March 2020, this decision was put on hold, since the events were still unfolding and there were no clear indications about the world situation by the second semester of 2020. At that point, the Congress already had early bird registrations completed. However, with the spread of the COVID-19 and the recommendations of health agencies and governments, an in-person edition of the Congress was definitely dismissed. From that moment, the Organizing Committee started to consider cancelling the Congress in 2020, to postpone the edition to 2021 or to host the Congress in 2020 in a virtual platform. Considering the importance of guaranteeing the safety of all the participants, the importance and impact of the Congress and the importance of providing continuing education for the forensic community in a year so greatly affected with the cancellation of several meetings, the Organizing Committee decided to host the Congress in 2020 in an online platform [13].

The 2020 SBCF Online Joint Congress was a three-day meeting, with workshops, thematic sessions and conferences. The conference was hosted online using Zoom ${ }^{\circledR}$ platform (https://zoom.us/meetings). Ten workshops were offered in the Congress first day: Evidences interpretation, Infringing conduct in adolescence, Ante mortem and Postmortem Forensic Toxicology, Validation of Analytical Methods in Forensic Chemistry, Stable Isotopes in Forensic Sciences, Investigation in the Dark Web, Portable Methods in Forensic Chemistry and Scientific Methods in Crime Scene Investigation [13]. During the Conference second and third days, twelve virtual thematic sessions were hosted simultaneously: Crime Scene Investigation and Forensic Ballistics, Legal Medicine, Legal Odontology and Forensic Anthropology, Environmental Crime Scene Investigation, Computer Forensics and Investigation in Audiovisuals and Electronics, Documentoscopy, Forensic Chemistry and Toxicology, Criminology and Forensic Psychology, Forensic Biometrics, Forensic Genetics, Errors in Forensic Science and the role of the Technical Assistant, Teaching in Forensic Sciences and Criminalistics in Latin America [13]. The session of Forensic Chemistry and Toxicology was the $7^{\text {th }}$ National Meeting of Forensic Chemistry (ENQFor). Each one of these twelve sessions hosted four or more talks with experts from Brazil and abroad. In addition to these sessions, four panels were held in the Congress, to discuss interdisciplinary, forensic topics of interest. These conferences discussed: the access to trends and perspectives of Forensic Sciences; expertise/investigation in Brazil; organized crime in Brazil and; the interface between investigative journalism and crime investigation [13]. 
The scientific program also included a special lecture on fake news and oral presentations sessions. Furthermore, during the online meeting, the fourth edition of the traditional ceremony of the "Prêmio Destaque Forense" award, granted by the SBCF during each biannual meeting since 2014, was also held [15]. The number of participants (including attendees and guest speakers) was 637, with 72 guest speakers from Brazil and 30 guest speakers from 13 countries (Switzerland, Canada, South Korea, Portugal, USA, Spain, Mexico, Australia, Chile, Argentina and Colombia) [13]. In the previous edition of the meeting, held in-person in 2018, the number of participants (including guest speakers) was of 364 , with 53 guest speakers. Among the attendees, there were undergraduate and graduate students, postdoctoral researchers, professors, experts with State and Federal Police and other forensic professionals [13]. The number of abstracts submitted and approved was 49, being 42 in the format of expanded abstracts and 7 in the format of platforms [13]. The organizing committee of the event adopted the model of "expanded abstracts", consisting in abstracts with the possibility of longer length and inclusion of figures and tables, with the latter being components that are not normally accepted in regular abstracts. Regarding abstract submission there was a great decrease compared to previous editions of the meeting that were held inperson: in 2020, 49 abstracts were accepted in contrast to 126 abstracts accepted in the edition of 2018. However, some reasons associated with this reduced number of works submitted for presentation might be the short timeframe for submission, due to the change from in-person to online event, and the restrictions imposed by the pandemic, suspending or restricting researches in many laboratories.

\section{INCREASING THE ACCESS AND SCIENTIFIC COMMUNICATION THROUGH ONLINE CONFERENCES}

An online conference has a high potential to promote national and international access to the event, with increased accessibility. Participants and speakers that would not have access to the in-person meeting have more chances to attend it online. Since there is no need to travel, no costs with transportation and accommodation and no need to have visas or passports to attend, the participation can be easier and limitations may be overcome for an increased number of attendees, including people from other regions in the world or with disabilities or vulnerabilities, for example $[2,16]$. Moreover, it is also a great opportunity to invite speakers from different countries, overcoming the physical distance, travelling issues and potential conflicts of agenda with other appointments. As an example, in the 2020 SBCF Online Congress, guest speakers and/or attendees from North America, South America, Asia, Europe and Oceania participated in the conference, which might not have been possible for an in-person conference.

A virtual conference in Forensic Sciences, such as in other Sciences, is also a great opportunity to foster international collaboration and rapid scientific communication. In Forensic Chemistry and Toxicology, there is a need for rapid communication and notification especially in some fields, such as in the notification of new synthetic drugs in forensic casework. This is of great interest for researchers, forensic chemists and toxicologists, law enforcement and public health agents and communities involved in this field. Therefore, online conferences can be a very useful tool for this purpose, making it possible hosting conferences and symposiums more frequently throughout the year and increasing the target audience. For example, biannual meetings could be hosted annually, alternating between online and in-person meetings. The potential to increase the target audience is also very beneficial, to promote the internationalization of these meetings and the exchange of information between forensic professionals. These professionals may be facing similar challenges in different countries or learn different strategies from other countries that could work in their casework, for example.

\section{OPPORTUNITIES FOR CONTINUING EDUCATION IN VIRTUAL CONFERENCES}

Continuing education is highly important for students and professionals involved with Forensic Sciences in order to promote the advance of the field [17]. In this case, continuing education opportunities in conferences, workshops and symposiums are an excellent way to keep updated or gain knowledge in a specific topic or theme. In addition, these opportunities can be even more interesting for those that 
were not able to attend an undergraduate or graduate program in Forensic Sciences but are interested in pursuing a career in this field. Educational programs (undergraduate and graduate) in Forensic Sciences are increasingly being designed and offered in many countries, but these specific programs may still be limited in some areas. Furthermore, in Forensic Sciences, certifying organizations may require continuing education and professional development for maintaining a certification of those certified professionals, which may include attending courses, workshops and conferences [18,19], such as the American Board of Toxicology [20] and the American Board of Forensic Toxicology (ABFT) [21] for example. During the scientific meetings promoted by associations partnered with these professional organizations, some activities grant continuing education credits, such as the ABFT, which accepts continuing education credits for the presentation of workshops, posters or platforms, for example, during the meetings of the American Academy of Forensic Sciences (AAFS), Society of Forensic Toxicology (SOFT) and The International Association of Forensic Toxicologists (TIAFT) [21]. In case these meetings are not offered by any reason or the professional is not able to attend the meeting, an invaluable opportunity for continuing education is missed.

Virtual conferences may offer the opportunity for participants to access recorded lectures, workshops and other activities hosted in the event, in alternative schedules or even after the end of the event. In the 2020 SBCF online meeting, the attendees had the possibility of access all the content of the event (which was previously authorized by the speakers and recorded) for up to 30 days after the end of the event (if member of the SBCF) or up to 10 days after the event (if non-member of the SBCF) [13].

\section{THE BENEFITS AND REQUIREMENTS OF VIRTUAL PLATFORMS VIRTUAL CONFERENCES}

Virtual conferences are hosted in online platforms, which can allow a number of benefits. For example, through virtual platforms, visualization and sharing of content and data can be easier and occur still during the conference [2]. The content of the presentations is displayed directly on the computer, tablet or smartphone screen. The use of the platform can also lead to a more rapid interaction between speakers, sessions chairs and audience, which can occur through chat or microphone/audio. The session chairs have more control of the questions and can organize the questions and answers sessions in a more effective way, grouping similar questions and optimizing time for more interactions. However, it is important to consider that each type of virtual platform has its own features and allows different types of interaction [6].

The use of virtual platforms also makes authorized recording of sessions easier, and the content can be offered for the attendees to watch or rewatch it on-demand after the conference [16]. During inperson meetings, in general, sessions are not recorded and the participants need to choose to watch one presentation over another when they are occurring simultaneously, while in the online conference, they can watch one session through live streaming and the other one on-demand after the conference. This is particularly interesting in the field of Forensic Sciences. As multidisciplinary events, Forensic Sciences meetings usually host a number of different thematic sessions. In the 2020 SBCF Online Congress, the majority of the guest speakers authorized recording their lectures in thematic sessions or workshops, which were made available for the attendees. However, the guest speakers because of ethical issues regarding images, videos or data, which is not unusual in Forensic Sciences, may not authorize recording their lectures, and some of the lectures may not be offered on-demand to the attendees. For this reason, it is very interesting to inform the participants in advance which sessions are not being recorded and which ones will.

It should be noted that despite the benefits, there are some requirements in regards to the online platform. Some aspects should be considered when designing an online event: potential audience size, duration of the event, interactivity, recording options and technical support. First, if the goal of the conference is to reach large audiences and have no limit of public, the organizing committee should search and use platforms with no public limitation or with high capacity, in order to avoid any issues or limitations in registrations. In regards to the duration of the meeting, a similar approach should be used and platforms with no time limitation are recommended, especially considering that delays may occur and alter the 
duration of each planned activity in the event. In addition to these topics, technical support is very useful, even for more experienced users of specific and on-line meeting platforms. It is recommended to have at least one technical staff in each virtual room of the conference, to support session chairs, guest speakers and attendees in case of any issue or to provide technical orientations. Although online meetings and classes are becoming more common nowadays, some people may not be familiar with new or less known platforms and having technical support is paramount. It is also a good strategy to keep a direct contact line between chairs of the sessions and technical staff, in case the chair of the session loses internet connection or similar issues. In this case, the session chair or moderator can easily communicate with the technical staff to communicate attendees and guest speakers. An interesting strategy adopted by the organizing committee of the 2020 SBCF Online Congress was to host a non-mandatory "training session" for all interested guest speakers, which were offered in different time-slots throughout two different days, in order to provide them with training in how to access and use the platform. Some of the speakers had interest in attending it and could train how to share their screen, see the attendees and more. The organizing committee organized two virtual rooms with a technical staff present and also provided the speakers with a guide and a tutorial to access the platform and use common tools such as microphone, video, screen share and chat. These approaches may be particularly interesting if a non-public available platform (e.g., an institutional platform) will be used for the conference.

There are several platforms available online, in free and paid versions. However, in general, most of these platforms have limited availability in free versions, limiting the use of it for large group meetings, during unlimited time and/or with technical support. For these reasons, it is more recommended to adopt paid versions of these platforms or to use alternative platforms that have no limitations on number of participants and time. In this context, it is important to find a platform that has these features.

\section{THE IMPACT OF MULTIPLE LANGUAGES IN ONLINE CONFERENCES}

The promotion of diversity and inclusion is very important in Science. There is a need for searching strategies and approaches to promote access for very diverse audiences. This is surely very beneficial in any field, including the Forensic Sciences, because it can increase the access to scientific advances and, at the same time, it can promote the discussion, exchange of information in a very open and diverse environment. Therefore, as mentioned before, hosting an international online conference is a powerful tool to promote these actions in Forensic Sciences. However, the language barrier can be a challenge to overcome.

A virtual conference is a great opportunity to foster international exchange of information and collaboration, including in Forensic Sciences. Offering translation and captioning during the presentations is a very useful and powerful tool to increase the access of people from different nationalities and/or with hearing or visual disabilities to these conferences [2]. This strategy applies not only to the attendees in general but also to guest speakers, and a diverse number of specialists from different nationalities can be invited to present and share their experiences. For example, one of the main characteristics of the SBCF biannual congresses is to offer translation of lectures and courses in English to Portuguese, to promote the inclusion and access to all the attendees who are not fluent in English, since the official language in Brazil is Portuguese. During previous in-person meetings, this service was offered and used by many attendees, who can attend the lectures of renowned specialists even without speaking the speaker's language. In the 2020 SBCF Online Congress, the translation services were offered for almost all panels, lectures and workshops presented in English or French. The sessions in Spanish were not translated because there is more similarity between Spanish and Portuguese languages. In virtual conferences, this service is easier to use, since no accessory is needed (such as the use of headphones for hearing the interpreter rather than the speaker during in-person meetings) and there are specific features in the platform that allow selecting the language.

It is important to note that the translation in an online conference involves the platform features, the technical staff and the interpreter. For this reason, previous tests before the conferences are useful to 
coordinate these actions, especially if the speaker or the interpreter have no experience with the platform used. In the 2020 SBCF Online Congress, the Zoom ${ }^{\circledR}$ platform was used for the conference and the attendee had the option to choose between listening to the guest speaker's audio or the interpreter's audio. The experience was positive and worked well for all the sessions. However, the translation increases the access to all sessions and, overall, to the Congress and, for example, in Brazil, this service is costly, especially for highly-trained professionals. Therefore, this needs to be considered when these services are required. On the other hand, with the development of new technologies, translation apps and softwares might be more available nowadays, which allow the reduction of the translation-related costs. In the 2020 SBCF Online Congress, based on the experiences of previous meetings with the presence of the interpreter and the lack of knowledge on translation apps, the interpreter was present for the translation, but it is important to highlight that there may be some alternatives to this approach. Overall, although there may be some limitation regarding costs with these services, the possibility of translation in the online conference has important benefits, increasing the access to all the sessions in a language other than the attendee's language and supporting the goal of reaching larger audiences, and therefore, the internationalization. This can lead to more diverse audiences and events that are more inclusive.

\section{POSTERS AND PLATFORMS PRESENTATIONS IN VIRTUAL CONFERENCES}

Posters and platform presentations are core sessions of many scientific conferences. In online formats, these sessions are different and may not offer the same level of interaction. On the other hand, during virtual conferences, abstracts, platforms and posters may be more easily accessible and be available longer, making it possible to attend oral and poster presentations that are occurring simultaneously [2]. For example, in the 2020 SBCF Online Congress, the organizing committee offered two options for submitting abstracts for presentation: expanded abstracts and recorded oral presentations. Expanded abstracts were available by the beginning of the conference in the abstracts book and oral presentations were exhibited during the event for all the attendees. The experience with these two formats were both successful and led to an important part of the congress. However, the direct interaction between presenters and attendees for questions and comments was missed.

In online conferences, it may be interesting to explore alternatives that allow the contact between presenters and audience conferences for questions and comments. In the event of the SBCF, due to the short time frame for restructuring the event, it was not possible to explore and search for different platforms that would allow the exhibition of posters and to host a session of oral presentations with time for questions (the oral presentations were prerecorded). For example, the presentations (poster or platforms) can be performed online, in which the attendees can see the poster or watch the presentation and ask questions to the presenter, who will be online in a specific period, such as in parallel virtual rooms [22]. For example, building a virtual exhibit hall for the event can be a strategy for fostering sponsorship opportunities [22]. In addition, if possible, this can also be a good strategy to exhibit posters submitted for presentation. For example, a virtual exhibit hall was implemented during the virtual event of the AAFS held in 2021 [12]. However, these strategies lead back to the discussion of which platform to select for the conference and it is important to consider the availability of technical resources for this. Although the level of interaction may not be the same when comparing online and in-person meetings, there are online tools that can provide a good level of interaction between presenters and attendees.

\section{PLANNING OF COSTS AND REGISTRATIONS IN VIRTUAL CONFERENCES}

In a fully online conference, there are no costs with venue and air tickets and hotels for guest speakers and organizers, which significantly reduce the overall costs of the event. In this sense, online conferences are usually less costly than in-person conferences for the organizing institutions [2]. However, as mentioned before, the "online facilities" have costs as well, including the platform and technical assistants. In addition, translation services, organizing companies and design and marketing services are still required and have costs as well. 
There are two options for online conferences in regards to the registrations: free or paid registrations. In the 2020 SBCF Online Congress, the organizing committee has decided to charge for the registrations but at a much smaller fee in comparison to an in-person meeting. This needs to be rationalized considering attendees will not be offered a "physical structure" for the event and will not have the social part of the conference, which demands costs as well. However, a free-of-charge conference may be more accessible and increase the number of attendees. In this case, the support from sponsors and from the organizing society are invaluable sources of resources to host the online conferences.

\section{PERSPECTIVES OF VIRTUAL CONFERENCES IN FORENSIC SCIENCES}

Distance education is a pedagogical method that has been in use for a long time and that has moved from correspondence-based to internet-based courses over the years [23]. This methodology is interesting in many situations such as for students with limited access to a university or time to attend an in-person course, for example [23,24]. With the pandemic of COVID-19, the inclusion of online learning in many sectors has been accelerated, including scientific conferences. These conferences are very important in many areas and are the way some scientific associations have to discuss the advancements in their fields. Although with the pandemic some of these conferences had to be cancelled or postponed, in some cases such as in the 2020 SBCF Congress, conferences were moved to a digital platform. The virtual format for conferences certainly has several benefits in regards to access to the conference, scientific communication and interactivity.

The promotion of diversity and inclusion in Sciences is paramount and has been increasingly discussed. The diversity in the scientific environment should be and will be increasingly focused and approached by researches and funding agencies [2]. In Forensic Sciences, diversity and inclusion should be increasingly promoted as well. This field has been attracting and fascinating many people over the years, in many countries, especially young people searching for a career and degrees. Unfortunately, not all regions in the globe have opportunities, programs and events in Forensic Sciences. However, the opportunity of virtual scientific meetings can change this landscape and offer alternative ways to attend these conferences and advance the knowledge in this field. These virtual conferences can reach larger audiences over the world and promote increased access to the Forensic Sciences. Reduced-cost or free registrations and translations are some of the strategies that certainly can make these virtual conferences more accessible to diverse and larger audiences. Ultimately, this can lead to increased accessibility and more diversity in the audience, and scientific communication to larger audiences.

The partnership with other scientific associations, institutions and sponsors in hosting online conferences can have benefits not only for the conference itself. As mentioned, when the conference is being hosted online, the extent of the conference is usually greater and more people can be reached. In this context, the publicizing of the organizing scientific societies and institutions is also increased. For example, when education institutions are sponsors of these conferences, there is an increased possibility of reaching potential students nationally and abroad. In addition, for scientific associations and certification associations, it is an increased opportunity to reach out for new members and to communicate the actions and projects of these institutions. For example, in the 2020 SBCF Online Congress, the SBCF offered special registration fees for members of other partner associations such as the Brazilian Society of Toxicology (SBTox) and the National Association of Federal Criminal Experts (APCF) [13].

Scientific communication and research collaborations can also be improved, reaching more people in the scientific community through virtual conferences. In the forensic community, these national and international collaborations are paramount, especially considering many aspects of the several disciplines within the Forensic Sciences. The need for effective and rapid notifications within the Forensic Sciences can help build a global network in several areas. Novel psychoactive substances, DNA analysis in human identification and sexual assault cases and cybercrimes are some examples of current topics of forensic interest that can reach more people and international stakeholders, benefiting the exchange of information and rapid notification. The potential of having presentations recorded can also benefit the 
scientific discussion after the conference, promoting the collaboration between different research groups, institutions and agencies. Furthermore, online conferences help in reduction of carbon footprint [2].

For the success of the conference, good planning and best practices should be adopted and performed. Sessions chairs, guest speakers and attendees should be oriented regarding the functioning of the virtual platform, the ways of interaction available and best practices for the event. A good practice is to prepare a material with recommendations for the guest speakers, including orientations regarding accessing the virtual room, installing the platform, minimal requirements for internet connection and other recommendations such as environmental light and sounds. The chairs of the sessions should have a clear protocol to coordinate each session, including introducing the speakers and interacting with the audience as well as with the technical staff when needed. Technical support is a key factor in online conferences and it is recommended to have this support available during the live conference, and testing sessions with hosts and guest speakers before the conference are recommended as well [25]. Another important point to highlight is to consider several different strategies of marketing the conference, to reach large target audiences [25]. This step is an important part of the conference and can directly affect the number of participants. In order to promote internationalization and increase the access, using several ways to divulge the conference, including social media, and eventually marketing in different languages may increase the probability of reaching a larger audience. It is also useful to create mechanisms for both speakers and participants being able to communicate their participation in the conference, creating a different level of interaction [25]. Social media (e.g., Facebook, Twitter and Instagram) has been growingly used by scientific organizations to communicate their activities and share information. In this edition of the event of the SBCF, the event was publicized via official website [13], through the official pages of the SBCF on Facebook (https://www.facebook.com/SociedadeBrasileiraDeCienciasForenses/), Instagram (https://www.instagram.com/sbcf.oficial/) and Linkedln (https://www.linkedin.com/company/sociedadebrasileira-de-ciencias-forenses/) and also through the official page of the event on Instagram (https://www. instagram.com/enqfor/). Therefore, this is a useful way to reach large audiences.

The experiences hosting online conferences in 2020 should not be completely replaced by in-person meetings in the near future, hopefully with the end of the pandemic of COVID-19. On the other hand, it is not the goal of this work to suggest the complete substitution of in-person conferences by virtual conferences. In-person conferences are invaluable sources of research communication and networking, with the unique possibility to host social activities to bring the forensic community together for more interactions. When the conference is held in-person, the attendees can meet their colleagues, friends and potential collaborators in the field. Another advantage is the possibility to interact directly with exhibitors in the booths, to discover new technologies and products offered by the company and to discuss potential collaborations. Some of these exhibitors usually bring instrumentations to the conference, demonstrating in-person how these instruments work, which allows a very helpful discussion for researchers and laboratories interested in those instrumentations. In addition, in-person conferences are a great way to promote the city/state/ country hosting the conferences, in social, economic and cultural aspects, which is only possible when these conferences are hosted in-person. Therefore, in-person meetings cannot be completely substituted. However, the gains obtained by online education strategies adopted in 2020 should be continuously adopted in the future.

Considering the benefits and limitations of both virtual and in-person conferences, there are some potential ways to promote the combination of these models, taking advantage of the benefits offered by both models. There are some potential ways to promote this. For example, it is possible to develop a hybrid model, where the attendees and speakers have the chance to attend the conference in-person or online [26]. If one is not able to attend the in-person conference then this person can register for the online conference and watch it live from home, office or laboratory. Another possibility is to include an onlineonly edition of these conferences, eventually between in-person conferences, in order to promote higher access to those not able to travel and attend in-person. 
In summary, the benefits of virtual conferences should be considered for future conferences in Forensic Sciences, as another mode of scientific communication and networking, with potential for increased accessibility and diversity. This format can be useful in fostering and supporting international and national partnerships and collaborations and delivering scientific content. These virtual models can also be combined with in-person models, bringing the advantages of both types of scientific conferences together and increasing the impact of the event.

\section{Conflicts of interest}

The authors declare no conflicts of interest.

\section{Acknowledgments}

The authors would like to thank all members of the Organizing and Scientific Committees, participants, guest speakers, partners, sponsors and AGeventos ${ }^{\circledR}$ for their collaboration in the success of the 2020 SBCF Online Congress $-4^{\text {th }}$ Meeting of SBCF and $7^{\text {th }}$ ENQFor. The authors also thank Ms. Adriana Gediel, director of $A$ Geventos ${ }^{\circledR}$, for gathering and providing the statistics of the events.

\section{REFERENCES}

1. https://www.who.int/emergencies/diseases/novel-coronavirus-2019/technical-guidance [Accessed 24 May 2021].

2. Sarabipour, S. eLife, 2020, 9, e62668 (https://doi.org/10.7554/eLife.62668).

3. Achakulvisut, T.; Ruangrong, T.; Bilgin, I.; Van Den Bossche, S.; Wyble, B.; Goodman, D. F.; Kording, K. P. eLife, 2020, 9, e57892 (https://doi.org/10.7554/eLife.57892).

4. https://tiaft2021.co.za/dear-tiaft-friends/ [Accessed 24 May 2021].

5. https://news.aafs.org/meeting-theme/73rd-aafs-annual-scientific-meeting-goes-virtual/ [Accessed 24 May 2021].

6. Fulcher, M. R.; Bolton, M. L.; Millican, M. D.; Michalska-Smith, M. J.; Dundore-Arias, J. P.; Handelsman, J.; Klassen, J. L.; Milligan-Myhre, K. C.; Shade, A.; Wolfe, B. E.; et al. Trends Microbiol., 2020, 28 (12), pp 949-952 (https://doi.org/10.1016/j.tim.2020.08.004).

7. https://www.iacft.online/programs-1 [Accessed 26 May 2021].

8. https://www.cfsre.org/continuing-education/2020-online-forensic-symposium-current-trends-inforensic-trace-analysis-archival/ [Accessed 23 May 2021].

9. https://www.cfsre.org/continuing-education/2020-online-forensic-symposium-current-trends-inforensic-toxicology-archival/ [Accessed 23 May 2021].

10. https://www.cfsre.org/continuing-education/2021-online-forensic-symposium-current-trends-in-seizeddrug-analysis-archival/ [Accessed 23 May 2021].

11. http://www.tiaft.org/free-professional-development-symposium-1.html [Accessed 24 May 2021].

12. https://aafs.org/common/Uploadedfiles/Meetings/2021Meeting/2021MeetingProgram.pdf [Accessed 23 May 2021].

13. https://www.enqfor2020.sbcf.org.br/ [Accessed 23 May 2021].

14. https://sbcf.org.br/ [Accessed 24 May 2021].

15. https://www.sbcf.org.br/premio2020 [Accessed 21 June 2021].

16. Robinson, S.; Baumhammer, M.; Beiermann, L.; Belteki, D.; Chambers, A. C.; Gibbons, K.; Guimont, E.; Heffner, K.; Hill, E.-L.; Houghton, J.; et al. The British Journal for the History of Science, 2020, 53 (4), pp 575-590 (https://doi.org/10.1017/S0007087420000497).

17. https://forensiceducation.cfsre.org/ [Accessed 23 May 2021].

18. Melbourn, H.; Smith, G.; McFarland, J.; Rogers, M.; Wieland, K.; DeWilde, D.; Lighthart, S.; Quinn, M.; Baxter, A.; Quarino, L. Forensic Sci. Int. Synerg., 2019, 1, pp 161-169 (https://doi.org/10.1016/j. fsisyn.2019.08.001). 
19. Cosbey, S.; Elliott, S.; Paterson, S. Sci. Justice, 2017, 57 (1), pp 63-71 (https://doi.org/10.1016/j. scijus.2016.10.003).

20. Brock, W. J.; Adam, A. P.; Woolley, H.; Sugimoto, T. Int. J. Toxicol., 2009, 28 (3), pp 147-150 (https:// doi.org/10.1177/1091581809337263).

21. https://abft.org/continuing-education/ [Accessed 1 April 2021].

22. Vervoort, D.; Ma, X.; Bookholane, H.; Nguyen, T. C. Am. J. Surg., 2020, 220 (6), pp 1539-1540 (https:// doi.org/10.1016/j.amjsurg.2020.07.008).

23. Dietrich, N.; Kentheswaran, K.; Ahmadi, A.; Teychené, J.; Bessière, Y.; Alfenore, S.; Laborie, S.; Bastoul, D.; Loubière, K.; Guigui, C.; et al. J. Chem. Educ., 2020, 97 (9), pp 2448-2457 (https://doi. org/10.1021/acs.jchemed.0c00717).

24. Casanova, R. S.; Civelli, J. L.; Kimbrough, D. R.; Heath, B. P.; Reeves, J. H. J. Chem. Educ., 2006, 83 (3), pp 501-507 (https://doi.org/10.1021/ed083p501).

25. Rubinger, L.; Gazendam, A.; Ekhtiari, S.; Nucci, N.; Payne, A.; Johal, H.; Khanduja, V.; Bhandari, M. Int. Orthop., 2020, 44 (8), pp 1461-1466 (https://doi.org/10.1007/s00264-020-04615-9).

26. Hanaei, S.; Takian, A.; Majdzadeh, R.; Maboloc, C. R.; Grossmann, I.; Gomes, O.; Milosevic, M.; Gupta, M.; Shamshirsaz, A. A.; Harbi, A.; et al. Disaster Med. Public Health Prep., 2020, pp 1-6 (https://doi. org/10.1017/dmp.2020.406). 